\title{
Malignant Melanoma of Small Bowel: A Rare Case
}

\author{
Kamal Bandhate ${ }^{1}$, Ashok Kumar Diwan ${ }^{2}$, Subeera Khan ${ }^{3}$ \\ ${ }^{1}$ Post Graduate, Department of Radiation Oncology, Govt. Medical College \& Hospital Nagpur, India, 2Prof. \& Head, Department of Radiation Oncology, \\ Govt. Medical College \&Hospital, Nagpur, ${ }^{3}$ Senior Resident, Department of Radiation Oncology, Govt. Medical College \& Hospital, Nagpur.
}

\section{Abstract}

Melanomas affecting the small bowel are usually metastasis from primary cutaneous lesions. A primary melanoma of the gastrointestinal tract is very rare with reported incidence of just 3\%. We present a case of small bowel melanoma with liver metastases. Primary malignant melanoma of the small intestine is quite rare with only a few cases reported in literature. Like its cutaneous counterpart, intestinal melanomas too remains an aggressive disease with a poor prognosis. The overall survival of malignant melanoma affecting the GI tract is 4 to 6 months with a survival rate of less than $10 \%$ at 5 years.

Keywords: Malignant Melanoma, Gastro Intestinal Tract, Small Bowel, Liver Metastases.

Corresponding Author: Dr. Ashok Kumar Diwan, Professor and Head, Department of Radiation Oncology, Govt. Medical College \&Hospital, Nagpur, Maharashtra, India.

Received: January 2020

Accepted: January 2020

\section{Introduction}

Malignant melanoma develops from melanocytes which are usually located in the skin, the eye's choroid, the meninges, and the anal margin. Melanoma of the GI tract represents 1 to $3 \%$ of the digestive tract cancers. ${ }^{[1]}$

Primary malignant melanoma of the small intestine is quite rare, only a handful of cases have been reported in literature. Like its cutaneous counterpart, intestinal melanoma too remains an aggressive disease with a poor prognosis. The survival of patients with melanoma affecting the GI tract is 4 to 6 months with an overall survival rate of less than $10 \%$ at 5 years. ${ }^{[1]}$

\section{Case Report}

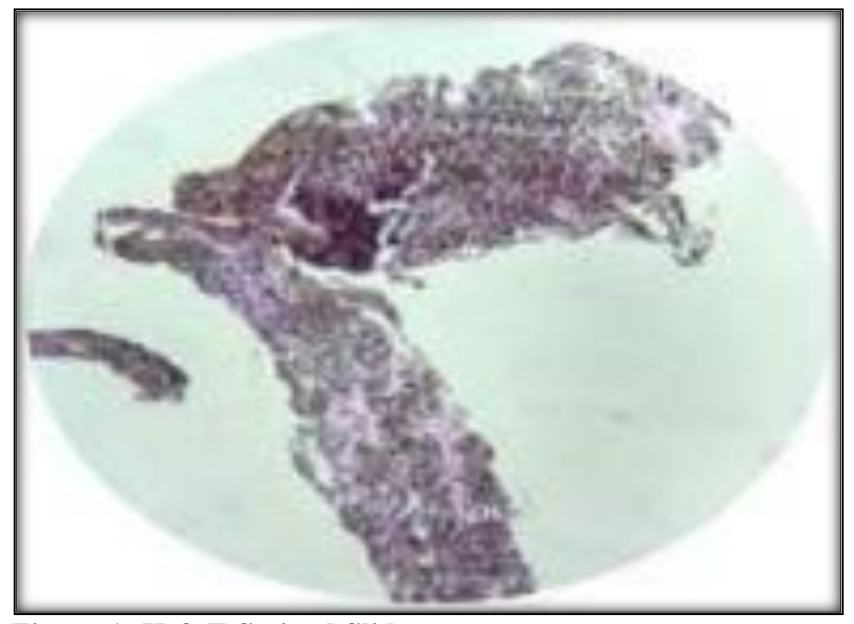

Figure 1: H \& E Stained Slide
We present a rare case report of a 48 year old man who presented with pain in abdomen and weight loss.

He already had underwent an ultrasound of the abdomen which was suspicious of liver metastases, before being referred to our side for further management.

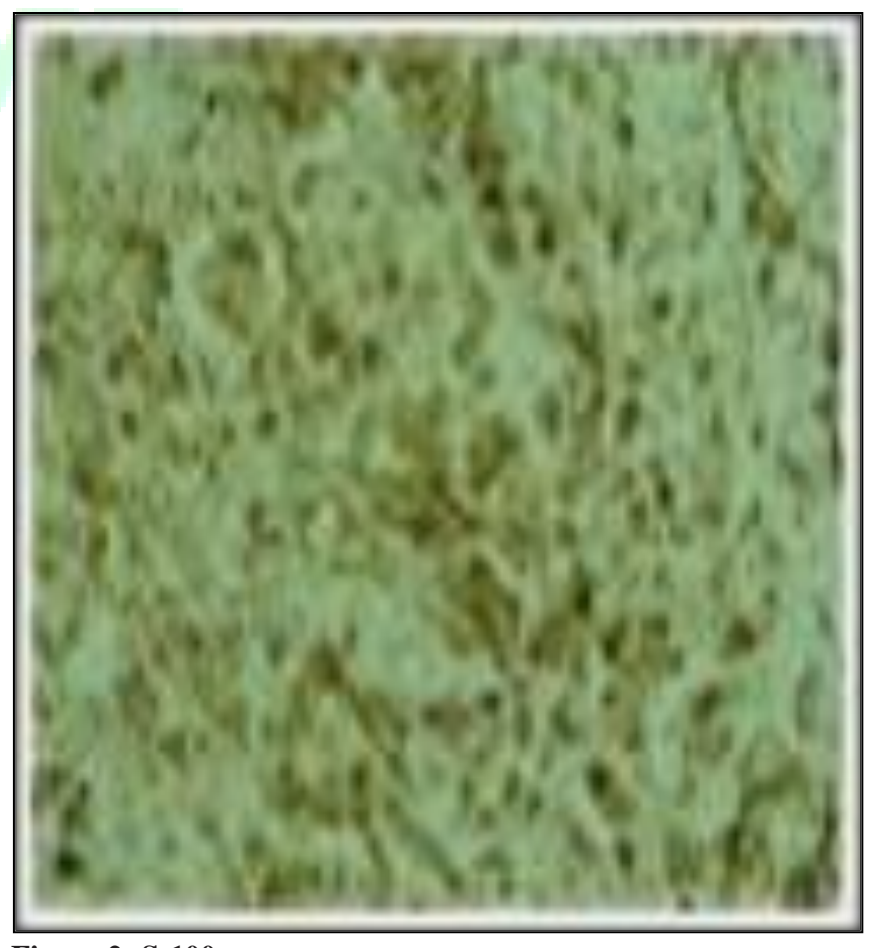

Figure 2: S-100

\section{Investigations:}

- Contrast Enhanced CT scan of the abdomen and pelvis 
failed to reveal any site of the primary. However multiple liver metastases were present in both lobes of liver, largest of size $3 \mathrm{X} 4 \mathrm{~cm}$ in left lobe.

- USG guided FNAC of the liver lesions was suggestive of melanoma.

- Careful clinical examination was done to rule out any cutaneous,ocular or anal lesions.

- Upper GI scopy showed multiple melanotic Patches (approx. 3mm in size at D1 and D2 and biopsies were taken.

- Histopathology showed malignant cells with coarse black melanin pigment in lamina propria and the diagnosis of malignant melanoma was established.

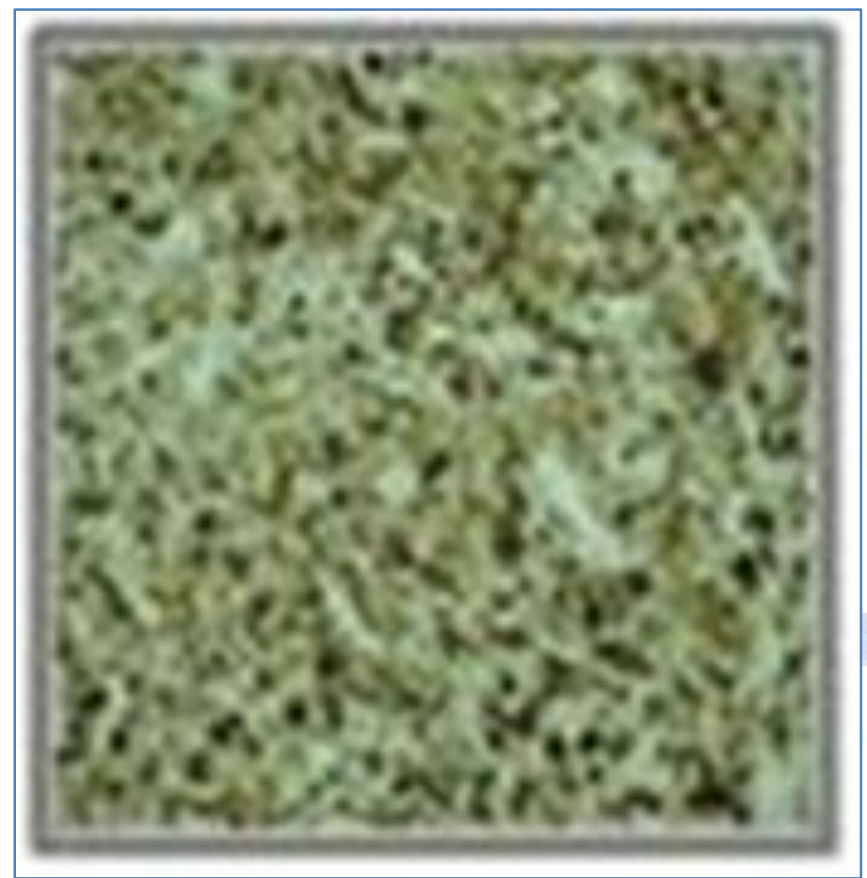

Figure 3: HMB45

- Immuno Histo Chemistry (IHC) markers were positive for S100 and HMB45.

- Patient was started on Dacarbazine based palliative chemotherapy.He has completed 2 cycles, and is now due for his $3 \mathrm{rd}$.

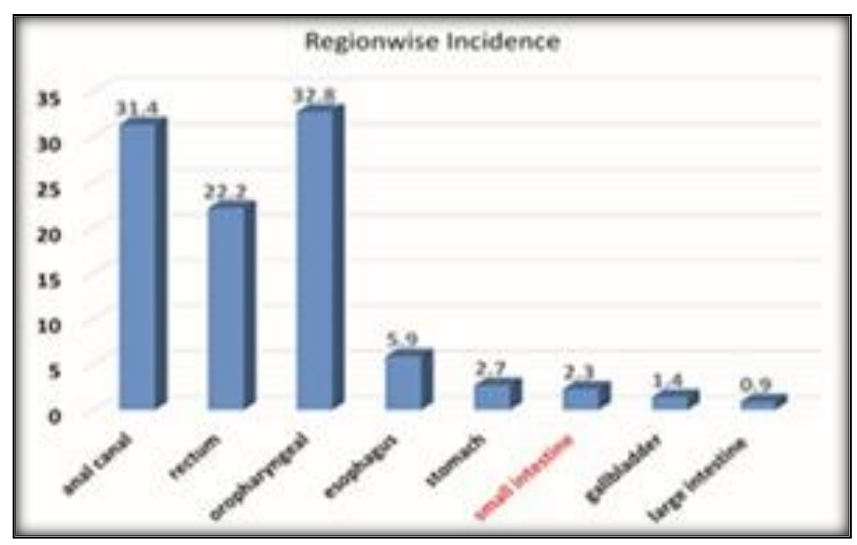

Graph: Site wise Incidence of Primary Melanoma

\section{Discussion}

Primary malignant melanoma of intestine can arise at any site within the GI mucosa, but it is found most commonly in ano-rectal (anal canal, 31.4\%; rectum, 22.2\%) and oropharyngeal $(32.8 \%)$ region, oesophagus $(5.9 \%)$, stomach $(2.7 \%)$, small intestine $(2.3 \%)$, gallbladder $(1.4 \%)$, and large intestine $(0.9 \%)$.

Melanoma develops primarily in the melanocytes, which are the dendritic cells present in the skin, the eye, the epithelium of the nasal cavity, oropharynx, anus, vagina, and the urinary tract. In addition to these sites, melanocytes are present in Meckel's diverticulum. ${ }^{[1]}$ Normally small intestine and colon do not contain melanocytes. Embryologically, the origin primary melanoma of small intestine is because of the melanoblastic cells of the neural crest that migrate to the distal ileum through the omphalomesenteric canal

There these cells differentiate by amine precursor uptake and decarboxylation (APUD), and can undergo neoplastic transformation in non-cutaneous site, ${ }^{[1]}$ although some authors still deny the existence of primary melanoma in the gastrointestinal tract. They argue that primary cutaneous tumors can regress before metastatic manifestations or they are too small to be identified by clinical and laboratory examinations. Primary or secondary gastrointestinal melanoma is very difficult to establish resulting in many controversies. $^{[1]}$ The gastrointestinal tract is the most common site for the metastases of cutaneous malignant melanoma. ${ }^{[1]}$ Metastases are usually asymptomatic and are diagnosed at autopsy in $58 \%$ of patients with cutaneous malignant melanoma. ${ }^{[1]}$ However, some gastrointestinal melanomas remain undocumented and without evidence of a primary lesion, cutaneous or elsewhere, even after a thorough examination. There are four different types of metastatic melanoma of the small intestine that are solely based on histopathological features: cavitary, infiltrating, eccentric, and polypoid. ${ }^{[1]}$ To make the diagnosis of primary malignant melanoma of the small intestine, one should exclude any history of melanoma in the other major sites.

It is very difficult to differentiate between primary intestinal melanoma and intestinal metastatic deposit of melanoma solely based on histopathological features alone.

Primary instestinal melanoma tends to be more aggressive and is associated with worse prognosis than cutaneous melanoma.

The mean age at the time of diagnosis of primary GI melanoma is around $54 \mathrm{yr}$ and $75 \%$ patients have mesenteric lymphadenopathy. ${ }^{[1]}$

According to Cheung et al. most common site being distal jejunum and ilium.

In our case, histological study confirmed the diagnosis of intestinal melanoma with concordant immunohistochemical profile; our patient had no history of cutaneous melanoma, and examination found no other sites of the disease.

\section{Conclusion}

In patients who have liver metastases with unknown 
primary, malignant melanoma albeit rare, should be kept in the list of differential diagnosis.

\section{References}

1. Elsayed AM, Albahara M, Nzeako UC, et al. Malignant melanomas in the small intestine: a study of 103 patients. Am J Gastroenterol 1996;91:1001-6.

2. Atmatzidis, K., Pavlidis, T., Papaziogas, B. et al. Surg Today (2002) 32: 831 .

3. Cheung MC, Perez EA, Molina MA, Jin X, Gutierrez JC, Franceschi $\mathrm{D}$, et al. Defining the role of surgery for primary gastrointestinal tract melanoma. J Gastrointest Surg. 2008;12:731-738.

4. Bloch T, Tejada E, Brodhecker C. Malignant melanoma in Meckel's diverticulum. Am J Clin Pathol. 1986;86:231-4.

5. DasGupta TK, Brasfield RD. Metastatic melanoma of the gastrointestinal tract. Arch Surg. 1964;88:969-73.
6. Krüger S, Noack F, Blöchle C, Feller AC. Primary malignant melanoma of the small bowel: a case report and review of the literature. Tumori. 2004;91(1):73-6.

7. Poggi SH, Madison JF, Hwu WJ, Bayar S, Salem RR. Colonic melanoma, primary or regressed primary. J Clin Gastroenterol. 2000;30:441-4.

8. Kadivar TF, Vanek VW, Krishnan EU. Primary malignant melanoma of the small bowel: a case study. Am Surg. 1992;58(7):418-22.

9. DasGupta TK, Brasfield RD. Metastatic melanoma of the gastrointestinal tract. Arch Surg. 1964;88:969-73. [

10. Bender GN, Maglinte DD, McLarney JH, Rex D, Kelvin FM. Malignant melanoma: patterns of metastasis to the small bowel, reliability of imaging studies, and clinical relevance. Am J Gastroenterol. 2001;96 (8):2392-400.

11. Cheung MC, Perez EA, Molina MA, Jin X, Gutierrez JC, Franceschi D, Livingstone AS, Koniaris LG, J Gastrointest Surg. 2008 Apr; 12(4):731-8.

Copyright: (C) the author(s), 2020. It is an open-access article distributed under the terms of the Creative Commons Attribution License (CC BY 4.0), which permits authors to retain ownership of the copyright for their content, and allow anyone to download, reuse, reprint, modify, distribute and/or copy the content as long as the original authors and source are cited.

How to cite this article: Bandhate K, Diwan AK, Khan S. Malignant Melanoma of Small Bowel: A Rare Case. Asian J. Med. Res. 2020;9(1):RO01-RO03.

DOI: dx.doi.org/10.47009/ajmr.2020.9.1.RO1

Source of Support: Nil, Conflict of Interest: None declared. 